\title{
Harmonization and standardization of immunogenicity assessment of biotherapeutic products
}

\author{
Meenu Wadhwa*,1 \& Robin Thorpe ${ }^{2}$ \\ ${ }^{1}$ National Institute for Biological Standards \& Control (NIBSC), Medicines and Healthcare Products Regulatory Agency, \\ Biotherapeutics Group, Blanche Lane, South Mimms, Potters Bar, Hertfordshire EN6 3QG, UK \\ ${ }^{2}$ Welwyn, Hertfordshire, UK \\ *Author for correspondence: Meenu.Wadhwa@nibsc.org
}

Understanding of the determinants of immunogenicity, the testing paradigm, the impact of antibody attributes on clinical outcomes and regulatory guidance is leading to harmonized practices for immunogenicity assessment of biotherapeutics. However, generation of robust immunogenicity data for inclusion in product labels to support clinical practice continues to be a challenge. Assays, protocols and antibody positive controls/standards need to be developed in sufficient time to allow assessment of clinical immunogenicity using validated methods and optimized protocols. Standardization and harmonization play a significant role in achieving acceptable results. Harmonization in the postapproval setting is crucial for a valid interpretation of the product's immunogenicity and its clinical effects. Efforts are ongoing to standardize assays where possible for antibody measurement and for measuring product/drug levels by producing reference standards. Provision of such standards will help toward personalized treatment strategies with better patient outcomes.

First draft submitted: 2 August 2019; Accepted for publication: 10 September 2019; Published online: 7 November 2019

Keywords: antibody panels $\bullet$ biosimilars $\bullet$ biotherapeutic products $\bullet$ clinical assessment $\bullet$ harmonization $\bullet$ immunogenicity • international standards $\bullet$ neutralizing antibodies $\bullet$ standardization

Nearly two decades ago, the incidence of pure red cell aplasia (PRCA) triggered by formation of neutralizing antibodies in chronic kidney disease patients treated with erythropoietin (EPO) stimulated intense interest in immunogenicity amid concern from industry and regulators [1]. A change in the regulatory assessment of biotherapeutic products followed and immunogenicity evaluation is now an important element of product approval. Since then, advances in immunogenicity testing and an increasing knowledge of risk factors has led to a greater understanding of the determinants of immunogenicity, the testing paradigm and the impact of antibody attributes on clinical outcomes.

On the regulatory front, specific guidance on immunogenicity assessment of biotherapeutic products [2-5] has been elaborated by leading regulatory agencies such as the EMA and US FDA. The primary objective is driven by the need to generate clinically relevant immunogenicity data pertinent for the product which postauthorization informs the prescriber of potential clinical outcomes if antibodies are induced and allows rational decisions to be made for patient treatment. Unfortunately, despite significant progress, a fundamental issue which has remained elusive in many instances is the generation of robust immunogenicity data for inclusion in product labels to support clinical practice $[6,7]$.

Consequently, various stakeholders (e.g., industry, regulatory agencies) are working together to harmonize practices where possible as evident from the numerous position papers and revised guidance [7-16]. Broadly, both the EMA and FDA guidelines are aligned and well-harmonized with respect to the principles of immunogenicity and the approach required for assessment (i.e., risk-based approach, a multitiered strategy for assessment, determination based on clinical studies). Both recognize the implementation for appropriate anti-drug antibody (ADA) sampling and characterization strategies in the clinical trial design and protocols in early development so clinically meaningful data can be obtained. Both advocate the development of positive controls/standards, the need for validated, highly 
sensitive, drug-tolerant assays for clinical studies, the use of harmonized terminology and reporting. Both require information on antibody incidence, titer, neutralizing capacity, transient or persistent, onset and duration and an integrated approach to data analysis with respect to clinical impact on pharmacokinetics, pharmacodynamics, efficacy and safety. A life-cycle management approach to immunogenicity through the creation of an integrated immunogenicity summary report that begins early and continues throughout product development and even postapproval is recommended. However, as expected, some distinct differences exist. The FDA provides more detailed and prescriptive information in its guidance which includes a specific guideline dedicated to assessment methods and their validation for the benefit of product developers $[4,5]$. In contrast, the EMA guidance is generalized (for the benefit of assessors in EU member states) and allows much-needed flexibility to developers in terms of practice (s) that could be adopted in the evolving area of immunogenicity to fulfil regulatory requirements. However, the general nature of the EMA guideline has required the adoption of a second, specific immunogenicity guideline dealing with therapeutic monoclonal antibodies [3]. This has not been found necessary for other product classes. While scientific advice from the EMA or product development meetings with the FDA can help to resolve any issues that drug manufacturers may encounter, nevertheless, further efforts are ongoing to harmonize and standardize approaches for immunogenicity assessment where possible.

\section{Harmonization of immunogenicity testing}

Harmonization of immunogenicity assessment can be considered to be desirable at various levels, namely harmonization of approaches for immunogenicity assessment, harmonization of assay strategies to attempt to have similar assay types across different products of the same product class, harmonization of immunogenicity study protocols in order to produce similar immunogenicity data and harmonization of assay methods to produce similar experimental results. Combination of these allows a valid overall assessment of the immunogenicity of the product.

It is widely accepted that assessment of clinical immunogenicity of a product requires a 'tiered approach' for detection of ADAs. This mainly includes a screening assay, a confirmatory assay, a neutralization assay and evaluation of antibody characteristics and titre. Figure 1 provides a schematic of a typical immunogenicity assessment strategy.

For screening, serum or plasma samples from patients are assayed for antibody to product using a screening assay which is known to detect all positive samples. As some of these will be false positives (normally around 5\%), these are eliminated by subsequently assaying all positive samples from the screening assay with a confirmatory assay, which eliminates false positives. A $1 \%$ false positive rate has been found acceptable by the FDA. This confirmatory assay normally is based on a competitive principle using product to compete for antibody. In the next step, positive samples are assayed for neutralizing capacity. Some proposed strategies include the use of a second binding assay, based on a different principle than the screening assay to confirm specificity. Other assays to further characterize the induced antibodies may be carried out at this stage, for example, for antibody class/subclass, avidity, cross reactivity/specificity - among others. although this may not be needed. Epitope mapping is very seldom requested but isotyping may be required in rare instances, for example, $\mathrm{IgE}$ isotyping may help to explain the occurrence of an anaphylactoid reaction following treatment with a product [18] and further identify patients at risk so mitigating strategies can be adopted.

While a range of bioanalytical platforms can be used for screening/confirmatory and neutralization assays, a carefully considered assay choice in terms of sensitivity and good drug tolerance is critical for ADA detection and its clinical relevance [17]. The EMA guidance on immunogenicity of monoclonal antibodies emphasises the importance of tailoring the assay strategy and the ADA assay(s) based on the product and the target population. Changes to the strategy during immunogenicity studies should nevertheless be avoided, but if refinements are found necessary, the changes must be shown not to influence the results obtained.

\section{Standardizing immunogenicity assays}

Consistency in immunogenicity assessment requires the use of standardized and harmonized protocols and assays. Although the immunochemical principles of assays used in immunogenicity assessment are similar to those which apply to other aspects of product characterization and development, there are particular challenges which make valid immunogenicity assessment difficult.

Immunogenicity assessment normally relies principally on measuring antibodies induced against product(s) in patients' serum or plasma. Such antibodies are heterogeneous, comprising immunoglobulins of different class and subclass with different light chains and allotypes. They differ in affinity for antigen and immunobiological properties. Some will neutralize the biological activity of the product (to varying degrees) whereas other will not, 


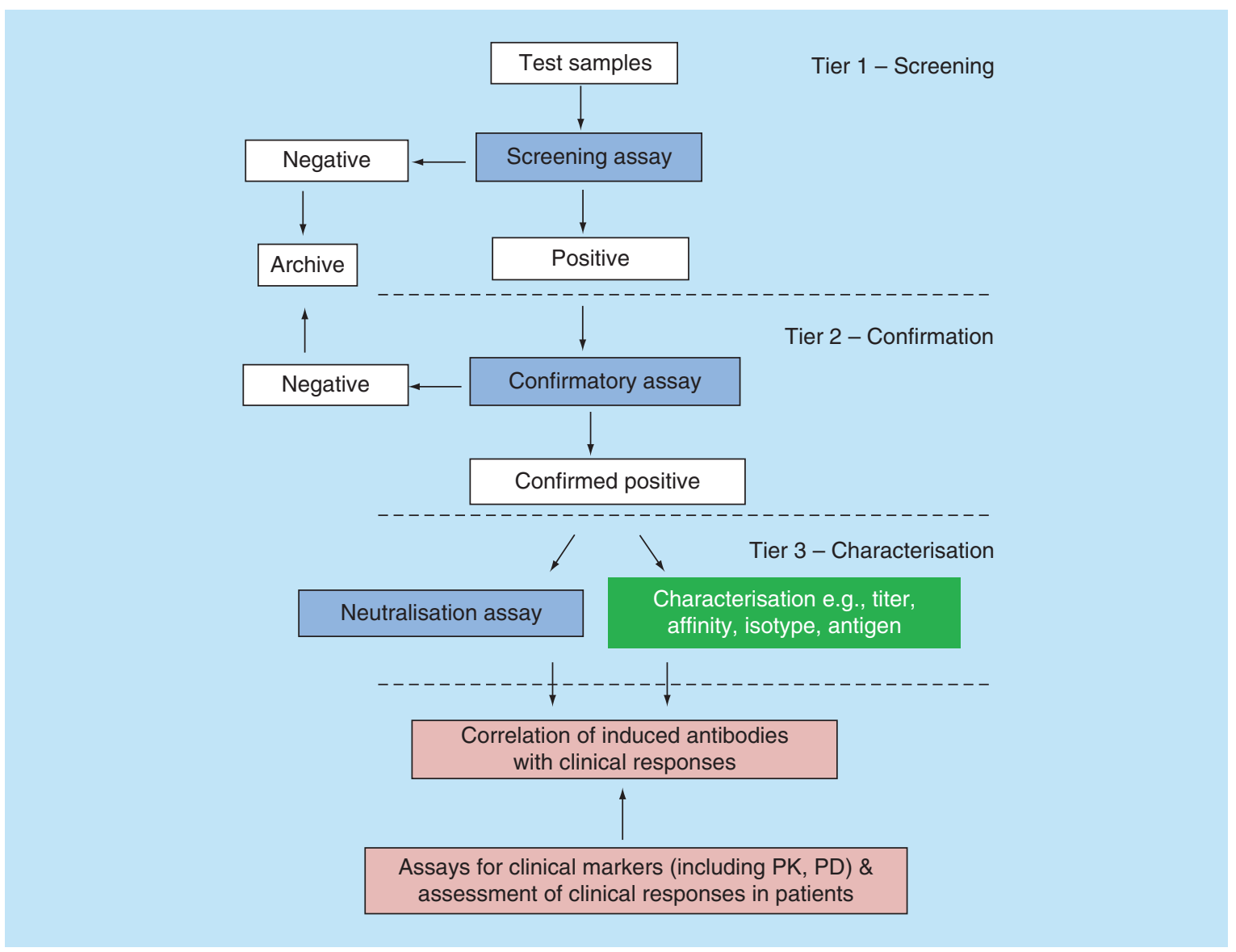

Figure 1. Proposed multitiered approach for immunogenicity assessment.

PD: Pharmacodynamics; PK: Pharmacokinetics.

Adapted with permission from [17] Crown (c) Elsevier Ltd (2015).

although they may bind with high avidity. The proportions of such antibodies can vary greatly between patients and individuals.

The 'classical' approach to standardization of biological and immunoassays requires assay calibration by including a comparison with appropriate standards. Such standards are selected to contain a known amount of the same substance as that being estimated in the unknown. In many cases, such as standards for biological potency assays used for biotherapeutic products, the choice of the standard is both obvious and easy. Standards are normally chosen so that the comparison with samples is 'like with like' This should normally result in a parallel response of the unknown test sample with the reference standard. This is, however, not the case for assays in use for measuring antibodies as part of immunogenicity assessment owing to the heterogeneous and variable nature of the antibodies produced in the patients. It is impossible to replicate the antibody content of standards with samples derived from patients and every sample is essentially unique in its antibody content. This results in a serious challenge when standardization of such assays is being undertaken as it is impossible to produce a standard for a true 'like with like' comparison. However, standardization of the assays is very important if valid and interpretable data are to be generated and so the challenge in standardization needs to be considered carefully, especially as the ideal for this is essentially unachievable.

Standardization approaches and standards used for the different assays employed for immunogenicity assessment can differ and so these are dealt with separately below.

\section{Screening assays}

Screening assays used in immunogenicity studies are normally immunoassays and most available immunoassay platforms/formats can be employed for this purpose. However, in practice, each of these formats has strengths and 
Table 1. Methods commonly used for screening and confirmatory assays and neutralizing assays.

\begin{tabular}{|c|c|c|}
\hline Assay type & Advantages & Disadvantages \\
\hline \multicolumn{3}{|c|}{ (A) Methods commonly used for screening and confirmatory assays } \\
\hline Direct ELISA & $\begin{array}{l}\text { Easy to use } \\
\text { High throughput } \\
\text { Inexpensive } \\
\text { Generic reagents and instrument }\end{array}$ & $\begin{array}{l}\text { High background } \\
\text { High risk of false positive results } \\
\text { Misses low-affinity antibodies } \\
\text { Antigen immobilization can mask epitopes } \\
\text { Requires species-specific secondary reagent } \\
\text { Not suitable for monoclonal antibody products }\end{array}$ \\
\hline Bridging ELISA & $\begin{array}{l}\text { Easy to use } \\
\text { High throughput } \\
\text { Inexpensive } \\
\text { More specific (dual-arm binding) and selective than } \\
\text { direct ELISA } \\
\text { Suitable for monoclonal antibody products } \\
\text { No requirement for species-specific secondary reagent } \\
\text { Generic reagents and instrument }\end{array}$ & $\begin{array}{l}\text { Impacted by therapeutic, serum components, for } \\
\text { example, anti-human Ig molecules, multivalent targets } \\
\text { Misses low-affinity antibodies } \\
\text { May not detect IgG4 and IgM } \\
\text { Antigen labeling may alter antigen }\end{array}$ \\
\hline $\begin{array}{l}\text { Electrochemiluminescence } \\
\text { (with direct/bridging format) }\end{array}$ & $\begin{array}{l}\text { High throughput } \\
\text { Large dynamic range } \\
\text { Minimally affected by matrix } \\
\text { High tolerance to therapeutic } \\
\text { Suitable for monoclonal antibody products } \\
\text { Detection signal consistent during life of TAG } \\
\text { conjugate }\end{array}$ & $\begin{array}{l}\text { Impacted by therapeutic, serum components, for } \\
\text { example, anti-human Ig molecules, multivalent targets } \\
\text { Misses low-affinity antibodies } \\
\text { May not detect IgG4 } \\
\text { Antigen labeling may alter antigen } \\
\text { Vendor-specific equipment \& reagents }\end{array}$ \\
\hline $\begin{array}{l}\text { Radioimmunoprecipitation } \\
\text { assay }\end{array}$ & $\begin{array}{l}\text { Moderate throughput } \\
\text { High sensitivity } \\
\text { Can be specific } \\
\text { Inexpensive }\end{array}$ & $\begin{array}{l}\text { Requires radiolabeled antigen } \\
\text { Requires special equipment and safety precautions } \\
\text { Decay of radiolabel may affect antigen stability } \\
\text { Can be isotype specific }\end{array}$ \\
\hline $\begin{array}{l}\text { Surface plasmon } \\
\text { resonance }\end{array}$ & $\begin{array}{l}\text { Moderate throughput } \\
\text { Determines isotype, relative binding affinity } \\
\text { Detects low affinity and high affinity antibodies }\end{array}$ & $\begin{array}{l}\text { Sensitivity less than other binding assays } \\
\text { Antigen immobilization may alter therapeutic } \\
\text { Regeneration step may degrade antigen } \\
\text { Vendor-specific equipment and reagents } \\
\text { Expensive }\end{array}$ \\
\hline \multicolumn{3}{|c|}{ (B) Methods commonly used for neutralizing assays } \\
\hline Cell-based bioassay & $\begin{array}{l}\text { Functional assay reflecting mechanism of action of } \\
\text { therapeutic } \\
\text { May correlate with clinical response }\end{array}$ & $\begin{array}{l}\text { Highly variable } \\
\text { Affected by serum (matrix) effects and interfering } \\
\text { factors, for example, therapeutic } \\
\text { Validation difficult, for example, cell-lines } \\
\text { Can have complex assay design }\end{array}$ \\
\hline Ligand binding assay & $\begin{array}{l}\text { Rapid, easy to use and validate } \\
\text { Simple assay design } \\
\text { Does not require cell-lines }\end{array}$ & $\begin{array}{l}\text { Impacted by therapeutic } \\
\text { Does no tprovide the true functional read-out of } \\
\text { cell-based assays } \\
\text { Antigen labeling may alter antigen }\end{array}$ \\
\hline
\end{tabular}

weaknesses. While there is no single overall advantageous assay, some procedures have been favored over others (Table 1). Importantly, assays can vary tremendously in their performance and their ability to detect antibodies of different characteristics. Therefore, it is now recognized that immunogenicity data are highly dependent on the assay used.

Selection of specific assays is usually based on several criteria including the nature of the product being investigated, the size of the study and available instrumentation. The data generated need to be statistically evaluated and this again may influence choice of the assay employed. When establishing the methods, other parameters including sensitivity, drug tolerance, target interference also need to be considered. Regardless of the assay choice, all assays for clinical immunogenicity should be suitable and validated with respect to several parameters including sensitivity, specificity, selectivity, precision, drug tolerance threshold.

Just like any other assay, a positive control/standard(s) is required for demonstrating assay performance and for assay validation. However, unlike most immunoassays which require standard(s) for assay calibration and for estimation of an amount in the sample, the lack or limited availability of human ADAs especially in sufficient volume, particularly during assay development and early studies and the problems of heterogeneity associated with polyclonal antibodies means that producing an ideal standard for such assays is impossible. Attempts to resolve these problems usually involve the use of specially prepared animal antisera, often purified and/or monoclonal antibodies specific for the product. But often the lack of similarity of such 'standards' and the samples can cause problems 
which must not be ignored. In some cases, reference panels of sera/purified antibodies/monoclonal antibodies with defined but variable characteristics are of particular value. For screening assays, such panels should comprise antibodies of different classes and subclasses, differing affinity/avidity and different titre/concentration. Specific antibody negative sera are also needed to serve as negative controls.

For routine monitoring of assay performance, inclusion of positive controls as performance indicators is especially useful. Such indicators are preparations with defined performance in assays. Their use as quality control samples is to show that the expected/required result is obtained in every assay performed. It is usual practice to produce performance indicators with different expected results, in other words, high, medium and low positive.

Calibration of antibody assays is a particular problem. It is clearly impossible to validly assign a mass for the antibody content in polyclonal preparations and in samples as these are heterogeneous. Therefore, expressing immunoassay results in 'mgs' of a 'positive control antibody' or reference standard is invalid. Alternative approaches are to assign standards arbitrary units of antibody or express data as titres which limits the use of standards for calibration, but problems arise with assay comparability/reproducibility. Use of performance indicators with defined expected titre can reduce this problem.

Confirmatory assays used in immunogenicity studies also need standardization and harmonization, but details of this are largely as for screening assays.

\section{Neutralization assays}

Neutralizing antibody assays are normally based on biological assays for the product or competitive ligand binding assays (the latter very often used for monoclonal antibody products). Standardization of the biological assay using an appropriate biological potency standard, often developed and characterized in-house or using publicly available standards (e.g., WHO International Standards or Pharmacopoeial Reference Preparations, e.g., for G-CSF and EPO) is relatively straightforward. Such standards can also be used to calibrate the assays. A useful way of expressing neutralizing capacity of antibody in a sample is to calculate the volume of the sample needed to neutralize a defined biological activity of the product. For the assay, a single concentration of the biological is selected and dilutions of each clinical sample assessed for reduction of the assay response. This allows determination of a neutralizing dose response of each sample and calculation of neutralizing capacity ('titre').

In all assay types, availability of a neutralizing antibody standard/positive control is useful for assay development, qualification/validation, assay performance and for routine use as quality control samples for monitoring the performance of the neutralizing assays. However, using this as a calibrant has the same problems as those for screening assays mentioned earlier. Reference panels and performance indicators for neutralizing assays may not be the same preparations as used for screening assays, but are equally valuable.

\section{Other assays}

Nonantibody assays, for example, bioanalytical assays which measure the pharmacokinetics (or drug levels) and pharmacodynamics are used in immunogenicity studies to attempt to correlate the induction of the immune response to the product with clinical effects in patients. Such assays should be suitable for use and accurate, precise, specific, sensitive and reproducible; the requirements of such assays are specified in appropriate EMA and FDA guidance. In both instances, assays must be standardized using appropriate in-house standards or WHO International Standards/Reference Reagents where available. For pharmacodynamics determination, assays clearly need to be tailored to the effects of the product and so no general details of required standards are possible.

\section{Harmonization of assay methodology}

Harmonization of assays allows a consistent immunogenicity assessment to be made. This requires standards as well as reference panels and performance indicators (as mentioned above). It also can be beneficial to use similar, or the same assay and share protocols if comparable data are to be generated. Within a laboratory, this is normally not a problem, but if assays are to be performed in different laboratories it can be challenging. Ensuring consistency of reagents used in all assays is essential, use of commercially available reagents can be problematical as sources of such reagents can change without this being evident to the user. Expression of assay data also needs harmonization where possible. 
Table 2. Assays used for biosimilars of Humira (information taken from European public assessment reports of the

different products from EMA website).

\begin{tabular}{|llll|}
\hline Biosimilar & Manufacturer & Screening assay & Neutralizing antibody assay \\
\hline Imraldi & Samsung Bioepis & ECL (1-assay) & Competitive ligand binding \\
\hline Cyltezo $^{1}$ & Boehringer Ingelheim & ECL (1-assay) & Cell-based ${ }^{\dagger}$ \\
\hline Amgevita/Solymbic & Amgen & ECL (1-assay) & Cell-based ${ }^{\ddagger}$ and ligand-binding \\
\hline Hyrimoz & Sandoz & ECL (1-assay) & Competitive ligand binding \\
\hline Hulio & Mylan & ECL (1-assay) & Competitive ligand binding ${ }^{\ddagger}$ \\
\hline Idacio & Fresenius Kabi Deutschland GmbH & ECL (1-assay) \\
\hline
\end{tabular}

Product withdrawn in Europe in 2019

Cell-based assays are recommended for monoclonal antibody therapeutics with cellular effector functions for clinical efficacy as the mechanism of action may not be adequately reflected in a noncell-based competitive ligand assay [2]. However, since evidence suggests that the binding specificity of the ADAs induced by adalimumab is mainly confined to the complementaritydetermining region [25], the competitive ligand binding assay is considered acceptable for detecting neutralizing antibodies.

$\dagger$ Antibody dependent cellular cytotoxicity assay.

$\ddagger$ Cell-based initially and superseded with ligand binding assay due to poor drug tolerance.

$\mathrm{ECL}$ : Electrochemiluminescence.

\section{Immunogenicity assessment of biosimilars}

Assessment of immunogenicity of biosimilars is challenging as it involves comparative testing with the reference product. The goal of the immunogenicity assessment is to demonstrate that there are no clinically significant differences between the biosimilar and the reference product [19-22].

The guidance recommends head-to-head comparative testing with the reference product in a homogeneous and sensitive population using the same sampling strategy and the same method(s). While the techniques for relative immunogenicity are the same as those in use for stand-alone products (Table 1), two different strategies can be adopted which vary in the choice of antigen used for assay [23,24]. The most thorough approach, the two-antigen assay, involves the use of assays based on the product which matches the product received by patients. Thus, patients treated with the reference product will be screened with an assay using the reference product as antigen whereas patients receiving the potential biosimilar will be screened using the biosimilar as antigen. This clearly avoids possible immunogenic differences between the two products and reflects true product immunogenicity. However, it involves establishing and carefully validating two different versions of the assays (one with each antigen) to exclude any bias in terms of sensitivity and drug tolerance. The alternative approach uses the same antigen for assaying all samples and this is acceptable providing the biosimilar is used as the antigen. This only involves development and validation of a single version of the assay but has the risk of overestimating the immunogenicity of the biosimilar. Nevertheless, it has become the norm and has been used in the assessment of several approved biosimilars. Table 2 provides limited information retrieved from European public assessment reports (unless specifically indicated) on the assays used in the assessment of adalimumab approved biosimilars.

For assays, suitable positive control antibodies may be generated against the biosimilar or the reference product. While the regulatory expectation is that assay validation and clinical assessment utilize the positive control that has been produced using the biosimilar product, in rare instances, commercially available antibodies against the reference product have been accepted on the proviso that comparable binding has been shown against the biosimilar and the reference product. Just like for stand-alone products, information on antibody incidence, titer, neutralizing capacity, transient or persistent, onset and duration, impact on pharmacokinetics and association with clinical sequela is required.

\section{Harmonization of testing in the postapproval setting}

Real world data show that the true immunogenicity of a product and the clinical implications become evident only postapproval when there is intense clinical use of the approved product. The multifactorial nature of immunogenicity together with the complexities of immunogenicity assessment implies that results from immunogenicity studies including clinical impact for the same product can be highly variable. Routine clinical monitoring is often undertaken in clinical laboratories to decide on treatment strategies for better disease management but difficulties arise when prescribers are confronted with published data which report conflicting results often due to use of an array of assays with different characteristics.

Since availability of a standardized assay or reference standards can help toward assay harmonization, efforts are ongoing in various laboratories toward harmonization strategies either at the assay level or by generating reference 


\begin{tabular}{|c|c|c|c|c|}
\hline Clone & Target & Isotype & Affinity & Neutralizing \\
\hline $3 F 5.1$ & High affinity receptor site 1 & $\lg G 1$ & Low & + \\
\hline $9 F 7.1$ & & $\lg M$ & Low & - \\
\hline 3A4.1 & Low affinity receptor site 2 & $\lg \mathrm{g} 4$ & High & + \\
\hline \multirow[t]{2}{*}{$8 \mathrm{C} 10.2$} & High affinity receptor site 1 & $\lg \mathrm{G} 1$ & High & + \\
\hline & & $\operatorname{lgG} 4$ & High & + \\
\hline \multirow[t]{2}{*}{$11 \mathrm{D} 12$} & Unknown & $\lg \mathrm{g} 2$ & Mod & + \\
\hline & & $\lg M$ & Mod & + \\
\hline
\end{tabular}

standards (which may likely suffer from the same problems as described earlier). Both require collaboration among various stakeholders, in other words, manufacturers, clinicians, clinical laboratories, diagnostic kit manufacturers and in some instances, even regulatory input.

\section{Toward standardization of an antibody assay}

The immunogenicity of IFN- $\beta$ products and the measures taken to facilitate the generation of a cell-based neutralizing assay, which, in conjunction with clinical outcomes should prove useful for clinicians treating multiple sclerosis patients with IFN- $\beta$ products serves as an excellent example of assay standardization. For IFN- $\beta$, antiviral assays have been the assay of choice for determining neutralizing antibodies. However, variations in cell-lines, cell-virus combinations and assay conditions between laboratories and use of novel assays have resulted in reporting of inconsistent antibody data for different products. Consequently, at the request of the Committee for Medicinal Products for Human Use (CHMP) of the EMA, manufacturers of IFN- $\beta$ products worked jointly (coordinated by Prof Huub Schellekens, University of Utrecht, The Netherlands) with help from the National Institute of Biological Standards and Control (NIBSC, UK, a World Health Organisation Collaborating Center) and contributed study data toward developing a harmonized neutralizing antibody assay. A panel of 62 blinded serum samples from IFN$\beta$-treated multiple sclerosis patients were assessed using different IFN- $\beta$ products in a qualified cell-based induced MxA protein measurement assay and results analyzed using a common statistical approach. The published study showed that although titres varied depending on the laboratory and the products used in the assay, the use of IFN$\beta 1$ a rather than IFN- $\beta 1 \mathrm{~b}$ as the challenge antigen produced more consistent results [27]. Since the standardized assay would provide comparable neutralizing antibody data, the EMA recommended the use of IFN- $\beta 1 \mathrm{a}$ in neutralizing antibody assays, independent of the product used for therapy, the provision of reagents (monoclonal antibodies for MxA protein ELISA, available from NIBSC) and validation of new neutralizing antibody procedures against the standardized assay described [28].

\section{Toward development of reference standards for antibody assays}

Therapy with human EPO, in rare instances, elicits neutralizing antibodies causing PRCA which requires clinical intervention. In recent years, an upsurge of antibody-mediated PRCA cases has been reported in unregulated markets following clinical use of products of divergent quality compared with the innovator product [29,30]. Underreporting due to use of inappropriate and/or insensitive assay methodologies for antibody measurement or lack of monitoring of the underlying cause of PRCA or even a general unawareness of clinical PRCA cases has caused some concern. It is clear however, that early antibody detection is of importance for patient management. For antibody detection, methods which differ in the types of antibodies they detect and in sensitivity are in use. Therefore, an antibody panel, comprising nine fully human monoclonal antibodies (appropriate for all erythropoiesis-stimulating agents, structurally related to human EPO), in collaboration with an EPO manufacturer [31], was established in 2015 as the WHO First international reference panel for EPO antibodies. Adoption of this panel, available from NIBSC, would facilitate consistency in detecting and measuring antibodies across different assay platforms for monitoring the safety and efficacy of erythropoiesis-stimulating agents [26].

The antibody panel, with defined characteristics (Table 3) representing those evident in antibody-mediated PRCA and non-PRCA patients (non-neutralizing, neutralizing, various isotypes, affinities) was evaluated using 


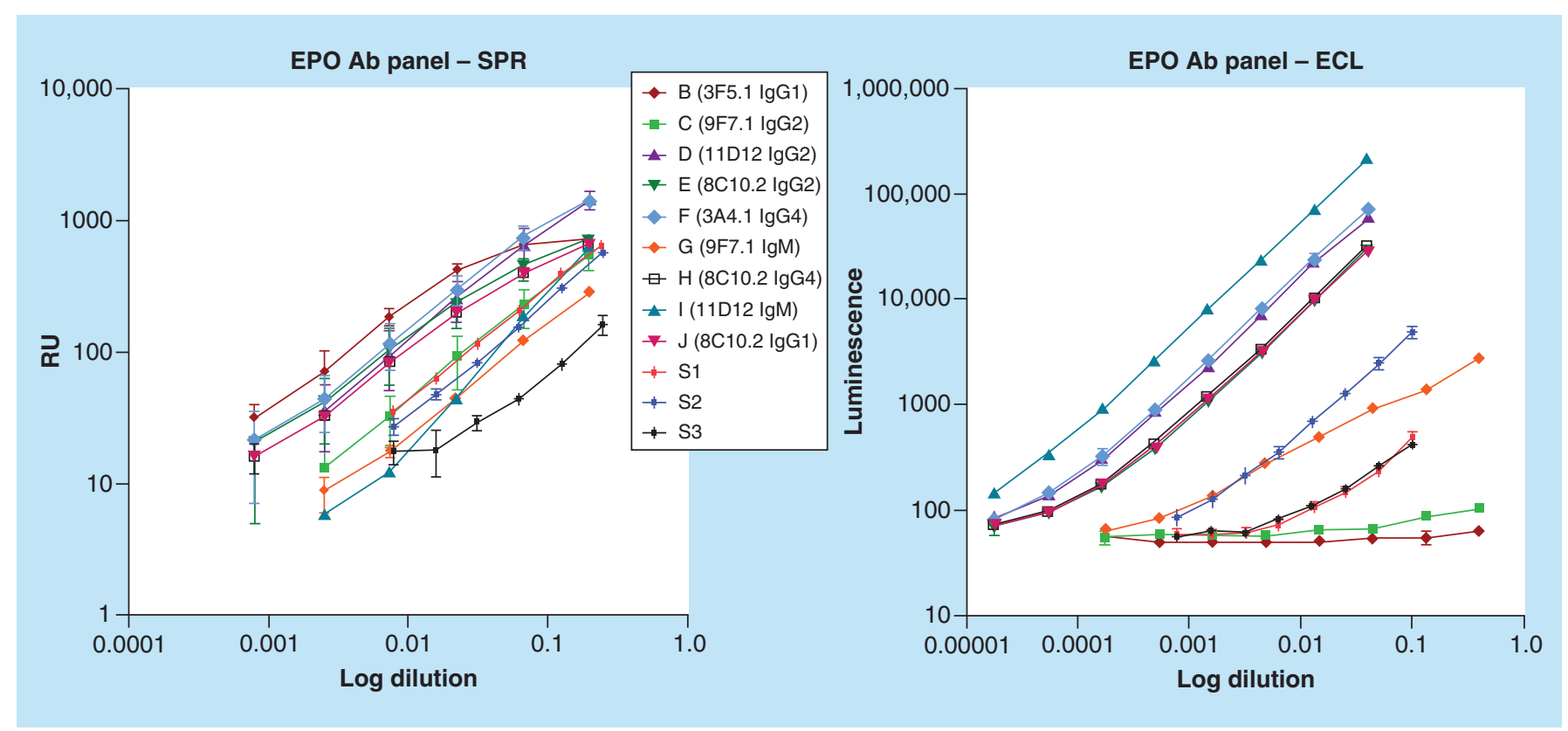

Figure 2. Data showing binding activity of the antibodies (B-J) and serum samples (S1-S3) using surface plasmon resonance and electrochemiluminescence platforms.

ECL: Electrochemiluminescence; EPO: Erythropoietin; SPR: Surface plasmon resonance.

different assay platforms in a large, multicentre international study. Binding assays, some using novel approaches and neutralization assays based on EPO responsive cell-lines were used. As expected, data on antibody detection and titre varied based on antibody characteristics and the detection method used. Of the methods tested, only selective platforms, for example, radioimmunoprecipitation and surface plasmon resonance were able to detect the diverse repertoire of antibodies in the panel. This indicated that some clinically relevant antibodies are likely to be missed in some assays routinely used for detecting EPO antibodies [26]. Figure 2 shows comparative data for the antibodies and serum samples using surface plasmon resonance and electrochemiluminescence platforms. These data were also confirmed in another study which showed the suitability of the biolayer-interferometry method to detect all the different antibodies [32]. Importantly, the study showed that all clinical PRCA samples were distinguished as antibody-positive and healthy donor serum as antibody negative across all different platforms tested. For neutralization, consistent results were seen across the assays for the different samples regardless of the cell-line and the assay conditions employed [26]. The heterogeneity seen in study data clearly indicates the need for reference standards for monitoring the performance and validation of antibody assays intended for clinical use and decision-making.

\section{Present \& future needs}

Presently, the complex landscape of biosimilar development and approvals has stimulated a lot of interest in standardization of assays for antibody detection and for measuring product/drug levels. The need for a reference antibody/panel for evaluating and comparing assays for a range of immunogenic biotherapeutics and possibly also to define clinical thresholds was emphasized by clinicians and product manufacturers at a workshop on immunogenicity assessment convened at the EMA (March, 2016). This is because therapeutic drug monitoring (TDM) which comprises measurement of product levels and induced antibodies is gaining momentum for rationalizing treatment strategies [33]. For example, for the anti-TNF monoclonal antibodies, adalimumab and infliximab, where immunogenicity can have clinical impact [34], professional associations have provided recommendations on TDM where possible as trough levels need to be within a certain therapeutic window for product efficacy [35,36]. However, challenges with producing accurate results due to different analytical testing methods in use in the clinical setting and the recognized lack of standardization of these methods [37] has delayed implementation of TDM in clinical practice. In the UK, the National Institute for Health and Care Excellence has produced TDM guidelines for anti-TNFs which advocate the need for standardization of assays (National Institute for Health and Care Excel- 
lence diagnostics guidance [DG22]) [38]. Such monitoring would allow for a personalized dose optimization or for treatment withdrawal/product switch with better patient outcomes.

It is therefore not surprising that various clinical groups have produced monoclonal antibodies for adalimumab and infliximab and further evaluated the functional characteristics of these antibodies. The suitability of these antibodies as ELISA reagents for monitoring drug levels or as standards for antibody assays has also been assessed [3943]. Two clinical groups have also urged the development and use of an anti-adalimumab international standard for assay harmonization $[41,43]$. In a comparison of a panel of 11 fully human anti-adalimumab antibodies (patientderived, with different affinities and directed against overlapping epitopes in the TNF binding region) in two binding assays; the bridging ELISA and the antigen binding test, Schouwenburg and coworkers showed that antibody detection is dependent on the affinity or both affinity and avidity of the antibodies based on the method used $[42,43]$. Additionally, nonparallel binding of the antibodies, similar to polyclonal antibodies was seen. Based on these results, they proposed the reporting of ADA values in appropriate arbitrary units rather than a mass value $(\mathrm{ng} / \mathrm{ml})$ while highlighting the issues that need to be considered in the selection of a standard for antibody testing [43]. Another group has developed and characterized a panel of antibodies with different characteristics against the anti-CD20 rituximab [44]. Furthermore, the Innovative Medicines Initiative (www.imi-europe.org) ABIRISK consortium (Anti-Biopharmaceutical Immunization: Prediction and analysis of clinical relevance to minimize the risk) have also generated and characterized human monoclonal antibodies against several therapeutic antibodies namely adalimumab, infliximab, rituximab, natalizumab with a view to standardizing antibody assays in the clinic [45].

As an extension of previous work, NIBSC is working jointly with most of these groups toward the goal of providing antibody standards for these products. The expectation is that these standards will be used by manufacturers of products, clinical laboratories (and diagnostic kit suppliers where appropriate) for evaluating assay characteristics and performance. In addition, adoption of the standards would provide assurance of results and facilitate comparability across different methods and laboratories and contribute to better clinical decision-making for the benefit of the patient.

Besides antibody standards, NIBSC is also engaged in a program on developing standards for monitoring product/drug levels in clinical patient samples. An international standard (coded 16/170) for infliximab was established in 2017 and is currently being used for calibrating immunoassays that are routinely used for testing of infliximab levels in patients [46]. An international standard for adalimumab has also been developed for TDM purposes with establishment of this standard (coded 17/236) by the WHO Expert committee of Biological standardization expected in October 2019 [47]. Implementation of these types of standards will help to standardize and harmonize clinical monitoring assays for informing clinical decisions and treatment strategies.

\section{Future perspective}

Despite significant advances in measuring antibodies, producing valid and interpretable immunogenicity data continues to be a challenge for all biologicals, and especially for biosimilars. Appropriate standardization and harmonization play a significant role in achieving acceptable results. It is important that assays and protocols are developed in sufficient time to allow the studies to be conducted with validated methods and optimized protocols. Standards and reagents for assays also need to be produced/identified in an appropriate time-frame and stored appropriately in sufficient amounts for the intended studies. Replacement of such substances needs careful planning.

Harmonization of protocols for immunogenicity assessment of stand-alone products and biosimilars is crucial if similar data are to be generated. Harmonization of the nonantibody assays is also essential for the same reasons. Assessment of the resultant data also need harmonization so that a consensus of the immunogenicity and its clinical effects can be validly made. NIBSC is currently engaging with various stakeholders with the aim of producing reference standards for immunogenicity assessment. Provision of such standards will support access to safe and effective medicines and help toward personalized treatment strategies with better patient outcomes.

\section{Crown copyright}

This work is licensed under Crown copyright protection and licensed for use under the Open Government Licence unless otherwise indicated. Where any of the Crown copyright information in this work is republished or copied to others, the source of the material must be identified and the copyright status under the Open Government Licence acknowledged. Published under CC-BY 4.0 www.nationalarchives.gov.uk/doc/open-government-licence/version/3/ @ Crown Copyright. 
Executive summary

Toward harmonization of immunogenicity assessment

- A greater understanding of the determinants of immunogenicity, the testing paradigm and the impact of antibody attributes on clinical outcomes is leading to harmonized practices in industry and across regulatory agencies.

EMA \& US FDA guidance are generally aligned

- Both use scientific and risk-based approach and have the same objective, in other words, to determine the risk of immunogenicity and the clinical impact. Some differences exist - the FDA has provided more detailed guidance versus the EMA. Both need an integrated analysis of immunogenicity, pharmacokinetics, pharmacodynamics, safety and efficacy.

Immunogenicity assessment strategy \& methodology for different assays

- These are broadly well-aligned but emphasis on assay methods with respect to sensitivity, drug tolerance, interference is increasing.

Standardization \& harmonization of assays for immunogenicity testing

- Consistency in immunogenicity assessment requires the use of standardized and harmonized protocols and assays, generation and choice of appropriate reference standards/reference panels for assessing assay performance and for assay validation. Reagent consistency is essential, sources of commercially available reagents can change without this being evident to the user. Expression of assay data also need harmonization where possible.

Immunogenicity testing of biosimilars

- Head-to-head comparison of immunogenicity needed using the same strategy and assay. Most biosimilar sponsors favor the one-assay approach but this still requires extensive validation to exclude any bias.

Harmonization of testing in the postapproval setting

- The variability in results for immunogenicity from studies using different assays has led to a demand for standardizing assays postapproval. Two different options have been adopted - availability of a common standardized assay for antibody detection as highlighted in the case of IFN- $\beta$ with the MxA protein neutralizing antibody assay; and development of antibody standards, for example, the provision of the First WHO reference panel for erythropoietin antibodies. As an extension of the latter, efforts are ongoing to standardize assays where possible both for antibody measurement as well as for measuring product/drug levels.

Financial \& competing interests disclosure

The authors have no relevant affiliations or financial involvement with any organization or entity with a financial interest in or financial conflict with the subject matter or materials discussed in the manuscript. This includes employment, consultancies, honoraria, stock ownership or options, expert testimony, grants or patents received or pending, or royalties.

No writing assistance was utilized in the production of this manuscript.

\section{References}

1. Casadevall N, Nataf J, Viron B et al. Pure red-cell aplasia and anti-erythropoietin antibodies in patients treated with recombinant erythropoietin. N. Engl. J. Med. 346(7), 469-475 (2002).

2. Guideline on immunogenicity assessment of therapeutic proteins. European Medicines Agency, London, UK (2017). www.ema.europa.eu/en/documents/scientific-guideline/guideline-immunogenicity-assessment-therapeutic-proteins-revision-1_en.pdf

3. Guideline on immunogenicity assessment of monoclonal antibodies intended for in vivo clinical use. European Medicines Agency, London, UK (2012). www.ema.europa.eu/en/documents/scientific-guideline/guideline-immunogenicity-assessment-monoclonal-antibo dies-intended-vivo-clinical-use_en.pdf

4. Guidance for industry. Immunogenicity assessment for therapeutic protein products. US Department of Health and Human Services, US FDA, Rockville, MD, USA (2014).

www.fda.gov/regulatory-information/search-fda-guidance-documents/immunogenicity-assessment-therapeutic-protein-products

5. Guideline on immunogenicity testing of therapeutic protein products - developing and validating assays for anti-drug antibody detection. US Department of Health and Human Services, US FDA, Rockville, MD, USA (2019). www.fda.gov/regulatory-information /search-fda-guidance-documents/immunogenicity-testing-therapeutic-protein-products-developing-and-validating-assays-anti-drug

6. Wang YM, Wang J, Hon YY et al. Evaluating and reporting the immunogenicity impacts for biological products - a clinical pharmacology perspective. AAPS J. 18(2), 395-403 (2016).

7. Shankar G, Arkin S, Cocea L et al. Assessment and reporting of the clinical immunogenicity of therapeutic proteins and peptides-harmonized terminology and tactical recommendations. AAPS J. 16(4), 658-673 (2014).

8. Stevenson L, Richards S, Pillutla R et al. White paper on recent issues in bioanalysis: focus on flow cytometry, gene therapy, cut points and key clarifications on BAV (Part 3 - LBA/cell-based assays: immunogenicity, biomarkers and PK assays). Bioanalysis 10(24), 1973-2001 (2018). 
9. Goodman J, Cowen S, Devanarayan V et al. Feedback from the European Bioanalysis Forum: focus workshop on current analysis of immunogenicity: best practices and regulatory hurdles. Bioanalysis 10(4), 197-204 (2018).

10. Gupta S, Richards S, Lakshmi L et al. White Paper on recent issues in bioanalysis: a global perspective on immunogenicity guidelines \& biomarker assay performance (Part 3 - LBA: immunogenicity, biomarkers and PK assays). Bioanalysis 9(24), 1967-1996 (2017).

11. Devanarayan V, Smith WC, Brunelle RL et al. Recommendations for systematic statistical computation of immunogenicity cut points. AAPS J. 19(5), 1487-1498 (2017).

12. Rup B, Pallardy M, Sikkema D et al. Standardizing terms, definitions and concepts for describing and interpreting unwanted immunogenicity of biopharmaceuticals: recommendations of the Innovative Medicines Initiative ABIRISK consortium. Clin. Exp. Immunol. 181(3), 385-400 (2015).

13. Gorovits B, Wakshull E, Pillutla R et al. Recommendations for the characterization of immunogenicity response to multiple domain biotherapeutics. J. Immunol. Methods 408, 1-12 (2014).

14. Schneider C, Papaluca M, Kurki P. A European perspective on immunogenicity evaluation. Nat. Biotechnol. 27(6), 507-508 (2009).

15. Koren E, Smith HW, Shores E et al. Recommendations on risk-based strategies for detection and characterization of antibodies against biotechnology products. J. Immunol. Methods 333(1-2), 1-9 (2008).

16. Wu B, Chung $S$, Jiang XR et al. Strategies to determine assay format for the assessment of neutralizing antibody responses to biotherapeutics. AAPS J. 18(6), 1335-1350 (2016).

17. Wadhwa M, Knezevic I, Kang HN, Thorpe R. Immunogenicity assessment of biotherapeutic products: an overview of assays and their utility. Biologicals 43(5), 298-306 (2015).

18. Chung $\mathrm{CH}$, Mirakhur B, Chan E et al. Cetuximab-induced anaphylaxis and IgE specific for galactose-alpha-1,3-galactose. N. Engl. J. Med. 358(11), 1109-1117 (2008).

19. Guideline on similar biological medicinal products containing biotechnology-derived proteins as active substance: non-clinical and clinical issues. European Medicines Agency, London UK (2014).

www.ema.europa.eu/en/similar-biological-medicinal-products-containing-biotechnology-derived-proteins-active-substance-non

20. Guideline on similar biological medicinal products containing monoclonal antibodies: non-clinical and clinical issues. European Medicines Agency, London UK (2012). www.ema.europa.eu/en/documents/scientific-guideline/guideline-similar-biological-medicinalproducts-containing-monoclonal-antibodies-non-clinical_en.pdf

21. Guidance for industry. Scientific considerations in demonstrating biosimilarity to a reference product. US Department of Health and Human Services, US FDA, Rockville, MD, USA (2015). www.fda.gov/regulatory-information/search-fda-guidance-documents/scienti fic-considerations-demonstrating-biosimilarity-reference-product

22. Guidance for industry. Clinical pharmacology data to support a demonstration of biosimilarity to a reference product. US Department of Health and Human Services, US FDA, Rockville, MD, USA (2016). www.fda.gov/regulatory-information/search-fda-guidance-doc uments/clinical-pharmacology-data-support-demonstration-biosimilarity-reference-product

23. Cai X-Y, Thomas J, Cullen C, Gouty D. Challenges of developing and validating immunogenicity assays to support comparability studies for biosimilar drug development. Bioanalysis 4(17), 2169-2177 (2012).

24. Ryding J, Stahl M, Ullmann M. Demonstrating biosimilar and originator antidrug antibody binding comparability in antidrug antibody assays: a practical approach. Bioanalysis 9(18), 1395-1406 (2017).

25. van Schouwenburg PA, van de Stadt LA, de Jong RN et al. Adalimumab elicits a restricted anti-idiotypic antibody response in autoimmune patients resulting in functional neutralisation. Ann. Rheum. Dis. 72, 104-109 (2013).

26. Wadhwa M, Mytych DT, Bird C et al. Establishment of the first WHO erythropoietin antibody reference panel: report of an international collaborative study. J. Immunol. Methods 435, 32-42 (2016).

27. Wadhwa M, Subramanyam M, Goelz S et al. Use of a standardised MxA protein measurement based assay for validation of assays for the assessment of neutralizing antibodies against Interferon- $\beta$. J. Interferon Cytokine Res. 33(11), 660-671 (2013).

28. European Medicines Agency (EMA) beta-interferons and neutralising antibodies (in multiple sclerosis), EMEA/CHMP/BWP/580136/2007 (2008). www.ema.europa.eu/en/documents/report/biologics-working-party-report-chmp-beta-i nterferons-neutralising-antibodies-multiple-sclerosis_en.pdf

29. Praditpornsilpa K, Tiranathanagul K, Kupatawintu P et al. Biosimilar recombinant human erythropoietin induces the production of neutralizing antibodies. Kidney Int. 80(1), 88-92 (2011).

30. Shin SK, Moon SJ, Ha SK et al. Immunogenicity of recombinant human erythropoietin in Korea: a two-year cross-sectional study. Biologicals. 40(4), 254-261 (2012).

31. Mytych DT, Barger TE, King $\mathrm{C}$ et al. Development and characterization of a human antibody reference panel against erythropoietin suitable for the standardization of ESA immunogenicity testing. J. Immunol. Methods 382(1-2), 129-141 (2012).

32. Shibata $\mathrm{H}$, Nishimura $\mathrm{K}$, Miyama $\mathrm{C}$ et al. Comparison of different immunoassay methods to detect human anti-drug antibody using the WHO erythropoietin antibody reference panel for analytes. J. Immunol. Methods 452, 73-77 (2018). 
33. Mitrev N, Van de Casteele $\mathrm{N}$ et al. Consensus statements on therapeutic drug monitoring of anti-tumour necrosis factor therapy in inflammatory bowel diseases. Aliment. Pharmacol. Ther. 46(11-12), 1037-1053 (2017).

34. Feuerstein JD, Nguyen GC, Kupfer SS et al. American gastroenterologic-al association institute clinical guidelines committee american gastroenterological association institute guideline on therapeutic drug monitoring in inflammatory bowel disease. Gastroenterology 153(3), 827-834 (2017).

35. Dreesen E, Bossuyt P, Mulleman D et al. Practical recommendations for the use of therapeutic drug monitoring of biopharmaceuticals in inflammatory diseases. Clin. Pharmacol. 9, 101-111 (2017).

36. Carlsen A, Omdal R, Leitao KO et al. Subtherapeutic concentrations of infliximab and adalimumab are associated with increased disease activity in Crohn's disease. Therap. Adv. Gastroenterol. 11, 1-11 (2018).

37. Kalden JR, Schulze-Koops H. Immunogenicity and loss of response to TNF inhibitors: implications for rheumatoid arthritis treatment. Nat. Rev. Rheumatol. 13(12), 707-718 (2017).

38. National Institute for Health and Care Excellence (2016). Diagnostics guidance [DG22]: therapeutic monitoring of TNF-alpha inhibitors in Crohn's disease (LISA-TRACKER ELISA kits, IDKmonitor ELISA kits, and Promonitor ELISA kits). www.nice.org.uk/guidance/dg22.

39. Van Stappen T, Brouwers E, Tops $S$ et al. Generation of a highly specific monoclonal anti-infliximab antibody for harmonization of TNF-coated infliximab assays. Ther. Drug Monit. 37(4), 479-485 (2015).

40. Bian S, Stappen TV, Baert F et al. Generation and characterization of a unique panel of anti-adalimumab specific antibodies and their application in therapeutic drug monitoring assays. J. Pharm. Biomed. Anal. 125, 62-67 (2016).

41. Gils A, Van de Casteele N, Poppe R et al. Development of a universal anti-adalimumab antibody standard for interlaboratory harmonization. Ther. Drug Monit. 36(5), 669-673 (2014).

42. van Schouwenburg PA, Kruithof S, Votsmeier $\mathrm{C}$ et al. Functional analysis of the anti-adalimumab response using patient-derived monoclonal antibodies. J. Biol. Chem. 289(50), 34482-34488 (2014).

43. van Schouwenburg PA, Kruithof S, Wolbink G et al. Using monoclonal antibodies as an international standard for the measurement of anti-adalimumab antibodies. J. Pharm. Biomed. Anal. 120, 198-201 (2016).

44. Tada M, Suzuki T, Ishii-Watabe A. Development and characterization of an anti-rituximab monoclonal antibody panel. MAbs 10(3), 370-379 (2018).

45. Innovative Medicines Initiative ABIRISK consortium [Anti-Biopharmaceutical Immunization: Prediction and analysis of clinical relevance to minimize the risk] www.imi.europa.eu/projects-results/project-factsheets/abirisk

46. Metcalfe C, Bird C, Dougall T et al. WHO ECBS Report on a Collaborative Study for Proposed 1st International Standard for Infliximab (2017). https://www.who.int/biologicals/expert_committee/BS2323_Infliximab_ECBS_2017_V.6.1.pdf

47. Wadhwa M, Bird C, Atkinson E et al. WHO ECBS Report on a Collaborative Study for Proposed 1st International Standard for Adalimumab (2019). www.who.int/biologicals/expert_committee/BS.2019.2365_Adalimumab_FINAL.pdf 